\title{
Effect of propofol and remifentanil on cerebral perfusion and oxygenation in pigs: a systematic review
}

\author{
Mai Louise Grandsgaard Mikkelsen ${ }^{1 *}$, Rikard Ambrus², James Edward Miles ${ }^{1}$, Helle Harding Poulsen', \\ Finn Borgbjerg Moltke ${ }^{3,4}$ and Thomas Eriksen ${ }^{1}$
}

\begin{abstract}
The objective of this review is to evaluate the existing literature with regard to the influence of propofol and remifentanil total intravenous anaesthesia (TIVA) on cerebral perfusion and oxygenation in healthy pigs. Anaesthesia has influence on cerebral haemodynamics and it is important not only in human but also in veterinary anaesthesia to preserve optimal regulation of cerebral haemodynamics. Propofol and remifentanil are widely used in neuroanaesthesia and are increasingly used in experimental animal studies. In translational models, the pig has advantages compared to small laboratory animals because of brain anatomy, metabolism, neurophysiological maturation, and cerebral haemodynamics. However, reported effects of propofol and remifentanil on cerebral perfusion and oxygenation in pigs have not been reviewed. An electronic search identified 99 articles in English. Title and abstract screening selected 29 articles for full-text evaluation of which 19 were excluded with reasons. Of the 10 peer-reviewed articles included for review, only three had propofol or remifentanil anaesthesia as the primary study objective and only two directly investigated the effect of anaesthesia on cerebral perfusion and oxygenation (CPO). The evidence evaluated in this systematic review is limited, not focused on propofol and remifentanil and possibly influenced by factors of potential importance for CPO assessment. In one study of healthy pigs, CPO measures were within normal ranges following propofol-remifentanil anaesthesia, and addition of a single remifentanil bolus did not affect regional cerebral oxygen saturation $\left(\mathrm{rSO}_{2}\right)$. Even though the pool of evidence suggests that propofol and remifentanil alone or in combination have limited effects on CPO in healthy pigs, confirmative evidence is lacking.
\end{abstract}

Keywords: Animal model, Brain, Oxygenation, Perfusion, Pig, Propofol, Remifentanil, Neuroanaesthesia

\section{Background}

Preservation of optimal cerebral perfusion and oxygenation (CPO) is the primary concern in assessing neurocritical patients undergoing surgery or sedation in the intensive care unit or for diagnostic procedures, and is equally important in both human and veterinary anaesthesia [1,2]. Animal models have been used increasingly over the last decade to study the significance of influential factors on cerebral haemodynamics and to achieve better understanding of mechanisms regulating $\mathrm{CPO}$.

\footnotetext{
*Correspondence: mailo@sund.ku.dk

1 Department of Veterinary Clinical and Animal Sciences, University of Copenhagen, 16 Dyrlægevej, 1870 Frederiksberg C, Denmark Full list of author information is available at the end of the article
}

Rodents and primates are widely used in neuroscience but recently the interest for use of pigs in neuroscience has increased. The pig is readily available through commercial sources and the gyrencephalic porcine brain resembles the human brain in several areas of gross anatomy, growth, and development [3]. The pig brain shows similarities in gyral pattern, distribution of grey and white matter, cerebral blood flow, and metabolism to the human brain. In addition, similarities in neurophysiological development and post-natal maturation with human brains are of value in human neuro-embryology and paediatric neuro-science [3-5]. Various porcine models have been described with the objective of CPO evaluation, but mostly they have been developed in the context of neurological trauma or diseases, such as traumatic brain injury 
$[6,7]$, subdural haematoma [8], intracranial hypertension $[9,10]$, as well as epilepsy [11] and stroke [12].

Cerebral perfusion and cerebral oxygenation are two separate measures that are often used simultaneously and sometimes interchangeably as clinical assessment measures to evaluate the physiological status of the brain. Both measures are used to assess the risk of ischemic brain damage and thus to predict clinical outcome and prognosis of the patient. The cerebral perfusion is often clinically assessed by evaluation of changes in the cerebral blood flow (CBF). Cerebral blood flow is controlled by homeostatic regulation of the cerebral perfusion pressure (CPP) and cerebral vascular resistance (CVR). Mean arterial blood pressure (MAP) and the intracranial pressure (ICP) are determinants of CPP giving $\mathrm{CPP}=\mathrm{MAP}-\mathrm{ICP}$, and $\mathrm{CBF}$ may therefore be assumed as $\mathrm{CBF}=\mathrm{MAP}-\mathrm{ICP} / \mathrm{CVR}$ [13-16]. Overall, several physiological or pathological conditions therefore may influence cerebral perfusion. Physiological alterations in blood pressure, cerebral metabolic rate, temperature, arterial carbon dioxide or oxygen contents, blood viscosity and pathological conditions such as hypertension, vascular disease, trauma or seizures all may influence perfusion [2, 13-16]. Mean arterial pressure can under normal conditions, and for patients in supine position, adequately represent the CPP for evaluation of CBF [16]. Clinically, CPP is used as an indirect index for CBF [17]. The maintenance of constant and stable CBF is essential for optimal cerebral metabolism and function, and is under normal physiological conditions secured by intrinsic cerebral autoregulatory mechanisms [16]. Cerebral autoregulation is the haemodynamic ability of the cerebral vasculature to maintain a constant CBF despite changes in blood pressure and consequently changes in MAP [18]. The limit of this preservative regulatory mechanism is generally observed in the MAP range of $50-150 \mathrm{mmHg}$. When MAP is above or below these values, CBF varies markedly with MAP, because the ability of the individual vessels to change in diameter has been exhausted [19].

Cerebral oxygenation represents a measure for the amount of oxygen actually available for consumption and energy metabolism in the cerebral tissue, and can be defined as either the brain tissue partial pressure of oxygen $\left(\mathrm{brPO}_{2}\right)$ [20], or as regional cerebral oxygen saturation $\left(\mathrm{rSO}_{2}\right)$ [21]. Venous jugular oxygen saturation $\left(\mathrm{SvjO}_{2}\right)$ normally provides an indirect measure for cerebral oxygen utilization, and thereby gives a qualitative assessment of CBF, but it is also used as a measure for global cerebral oxygen saturation. These parameters represent the oxygen content available within the tissue or in the vascular circuit, and are therefore dependent on CBF $[1,14,22,23]$.
Different methods and technologies have been established for the quantification and evaluation of cerebral haemodynamics, but no gold standard method has been fully validated to date, which makes comparison between the results of different studies challenging $[1,24,25]$. Historically, CBF has been studied by technically advanced methods like the nitrous oxide method [26], the krypton uptake method [27] or xenon 133 injection method [28, 29], but can be evaluated by modern techniques such as transcranial Doppler ultrasonography, laser Doppler flowmetry (LDF), positron emission tomography scanning, functional magnetic resonance imaging $[14,15,20]$ or laser speckle contrast imaging [30,31].

Target ranges for cerebral monitoring have been defined for healthy humans (Table 1), but are less well defined for pigs, which should be considered when assessing CPO in porcine models. CBF in pigs has been reported to decrease with age, being approximately 48,44 and $27 \mathrm{ml} / \mathrm{min} / 100 \mathrm{~g}$ in newborn, juvenile and adult pigs respectively [32], and thus may be comparable to the values identified in humans (Table 1).

Normal target values for $\mathrm{SvjO}_{2}$ during anaesthesia have not been defined in pigs but Mutch et al. [33] and two studies included in this review reported mean values between 74.3 and $82.7 \%$ (Table 6), and CPP has been found to vary with anaesthesia [34]. For brPO $\mathrm{P}_{2}$, normal values in pigs have been found to be $25-30 \mathrm{~mm} \mathrm{Hg}$ [35], which is similar to the range defined in humans (Table 1). Regional cerebral oxygen saturation measured by near infrared spectroscopy (NIRS) is simple, continuous and non-invasive and widely used in human neuroanaesthesia. Thus, it has been suggested that NIRS has potential as a central modality in the cerebral monitoring strategy [21]. NIRS has also been investigated in pigs and a

Table 1 Target ranges for anaesthesia related cerebral perfusion and oxygenation measures in humans

\begin{tabular}{llll}
\hline Target & Measure & Limits & Reference \\
\hline CerAutoReg $^{\mathrm{a}}$ & $\mathrm{mm} \mathrm{Hg}$ & $50-150$ & {$[18]$} \\
$\mathrm{MAP}$ & $\mathrm{mm} \mathrm{Hg}$ & $>80$ & {$[18,93]$} \\
$\mathrm{CPP}$ & $\mathrm{mm} \mathrm{Hg}$ & $50-70$ & {$[14,17]$} \\
$\mathrm{rSO}_{2}$ & $\%$ & $60-80$ & {$[22,90]$} \\
$\mathrm{SvjO}_{2}$ & $\%$ & $50-75$ & {$[15,22]$} \\
$\mathrm{brPO}_{2}$ & $\mathrm{~mm} \mathrm{Hg}$ & $25-50$ & {$[17,90]$} \\
$\mathrm{CBF}$ & $\mathrm{ml} / \mathrm{min} / 100 \mathrm{~g}$ & $25-50$ & {$[94]$} \\
CarotidBF & $\mathrm{ml} / \mathrm{min}$ & $275 \pm 52$ & {$[95]$} \\
\hline
\end{tabular}

$M A P$ : mean arterial pressure; ICP: intracranial pressure; $C P P$ : cerebral perfusion pressure; $\mathrm{rSO}_{2}$ : regional cerebral oxygen saturation; $\mathrm{SvjO}_{2}$ : jugular venous oxygen saturation; $b r P O_{2}$ : brain tissue partial pressure of oxygen; $C B F$ : cerebral blood flow; CarotidBF: carotid blood flow

a Upper and lower limits for cerebral autoregulation-highest in newborn lowest in adults 
normal value of $65 \%$, has been suggested [36], ranging from 57 to $72 \%$. In piglets, an ischaemic threshold of $35 \%$ has also been suggested [37].

Most studies investigating CPO in porcine models are carried out in anaesthetized animals. General anaesthesia aims at depressing consciousness and cerebral activity. General anaesthesia influences systemic cardiovascular function and consequently will affect CPO. However, when properly monitored and managed, general anaesthesia should not alter CPO significantly in the healthy brain $[38,39]$. The choice of anaesthesia should be evaluated when assessing studies evaluating CPO. Consideration should be given both to the isolated effect of single anaesthetic drugs, drug combinations as well as systemic physiologic status [39].

Inhalation anaesthesia elicits a dose-related suppressive effect of cerebral metabolism, but also has a direct dilating effect on the cerebral vessels that potentially will increase CBF. The net effect on CBF will be determined by dominating force of these competing and opposing effects $[14,40]$. The general assumption is that most intravenous anaesthetic drugs will cause an indirect and dose-dependent decrease in CBF by decreasing cerebral metabolism [18, 41-44]. Only ketamine seems to be an exception to this, by expressing the opposite effect on cerebral metabolism, and thereby increasing CBF [43, 45]. Opioids in general are believed to have minimal effect on CBF in clinical doses, but their effect on cerebral haemodynamics may vary depending on patient status and anaesthetic drugs used [14].

The choice between inhalation and intravenous anaesthesia in neurosurgery is debated and even though no single anaesthetic drug or regimen appears absolutely superior to others [39], an increasing tendency to use intravenous protocols as the basic regimen for neurosurgical anaesthesia, has been reported [46-49]. Significant differences in baseline measurement of MAP and CPP between inhalation anaesthesia and total intravenous anaesthesia (TIVA) in piglets have been reported, but no differences in CBF or $\mathrm{PbrO}_{2}$ were however evident between the anaesthesia regimens [34].

Total intravenous anaesthesia (TIVA) with a combination of propofol and remifentanil is an anaesthetic regimen that is widely used in neuroanaesthesia, and has advantages over inhalation anaesthesia (sevoflurane and isoflurane) with regard to desirable traits like fast recovery, a low incidence of nausea and vomiting, anticonvulsive potential, preservation of cerebral autoregulation and neuroprotection [40,49-51]. Propofol is the most widely used intravenous anaesthetic agent in both human and veterinary medicine $[49,52-54]$. Due to its global depressant properties in the central nervous system, it acts as a very potent hypnotic agent, which can be used for both induction and maintenance of general anaesthesia, and for sedation. Its favourable pharmacokinetic profile ensures a fast onset of action and rapid recovery even after prolonged administration [55]. Propofol may indirectly reduce $\mathrm{CBF}$ mainly due to depression of the systemic blood pressure $[53,55]$. The hypotensive effect is caused by a decrease in sympathetic activity and intracellular calcium flux resulting in vasodilation [55]. In pigs, the vasodilation caused by propofol has also been related to release of nitric oxide by the vascular endothelium [55]. Propofol has little or no effect on the conductive system of the heart and does not cause myocardial depression, but inhibits the tachycardiac response to hypotension by inhibition of the baroreceptor reflex $[53,55]$. The overall cerebral effect of propofol has been demonstrated to reduce $\mathrm{CBF}$, cerebral metabolic rate of oxygen and intracranial pressure, but it also acts as an antioxidant and has neuroprotective properties [53, 56, 57]. Remifentanil is an ultra-short-acting opioid with very potent and selective $\mu$-receptor agonist activity. It is preferred to fentanyl or other opioids due to its non-organ specific metabolism by blood and tissue esterases, which consequently results in a faster clearance and thereby faster recovery independent of infusion duration [58]. The main cardiovascular impact of remifentanil is dominated by moderate bradycardia and a marked decrease in systemic blood pressure. The use of remifentanil in humans thus, has an increased incidence of hypotensive periods in comparison with other opioids $[58,59]$. In contrast to this and compared to fentanyl-sevoflurane, remifentanil-propofol anaesthesia is in human clinical studies also reported to increase the incidence of arterial hypertension, hence the influence of remifentanil on CPO is somewhat unpredictable and may depend on the anaesthetic agent used [59]. In humans low and moderate dose remifentanil caused increase in regional CBF while remifentanil in high, supra-clinical doses caused a decrease in regional $\mathrm{CBF}$ [59], and no impairment of the cerebrovascular carbon dioxide reactivity [60]. It has been suggested that remifentanil in general decreases the cerebral metabolic rate of oxygen and only has minimal effect on intra cranial pressure $[59,61]$ and that the combined use of propofol and remifentanil preserves and improves cerebral autoregulation [59]. The overall effects of propofol and remifentanil on CBF and cerebral autoregulation in selected animal species are summarised in Table 2. Since the pig is increasingly of interest as a translational model in neurocritical research, it is important to reveal whether propofol and remifentanil influence $\mathrm{CPO}$ differently in pigs compared to humans. The objective of this review is to evaluate the existing literature with regard to the influence of propofol and remifentanil TIVA on cerebral perfusion and oxygenation in healthy pigs. 
Table 2 Summary of the effects of propofol and remifentanil on cerebral blood flow and cerebral autoregulation in selected animal species used in experimental neuroscience

\begin{tabular}{|c|c|c|c|c|c|c|}
\hline \multirow[t]{2}{*}{ Species } & \multicolumn{3}{|c|}{ CBF } & \multicolumn{2}{|l|}{ CA } & \multirow[t]{2}{*}{ References } \\
\hline & $\mathbf{P}$ & $\mathbf{R}$ & PR & $\mathbf{P}$ & PR & \\
\hline Humans & $\downarrow$ & $\uparrow \downarrow^{*}$ & $\downarrow$ & Preserved & Preserved & {$[18,52,55,56,58]$} \\
\hline Dog & $\downarrow$ & $\downarrow$ & $\cdot$ & Preserved & $\cdot$ & {$[96,97]$} \\
\hline Rabbit & $\downarrow$ & . & - & $\cdot$ & - & [98] \\
\hline Rat & $\downarrow$ & . & . & Preserved & . & [99] \\
\hline
\end{tabular}

CBF: cerebral blood flow; $C A$ : cerebral autoregulation; $P$ : propofol; $R$ : remifentanil; $P R$ : propofol-remifentanil combination; $\uparrow:$ increased; $\downarrow$ : decreased; $\bullet:$ uncertain; *: dose dependant

\section{Search strategy}

On May 10th 2016, an electronic database search was made in Agricola 1970 to April 2016, Agris 1975 to March 2016, Biosis Previews 1969-2009, CAB Abstracts 1910-2016 week 17, Embase 1974-2016 May 9th, International Pharmaceutical Abstracts 1970-April 2016, Zoological Record 1978-2009, Epub ahead of print, Inprocess and Other non-indexed citations, MEDLINE daily and MEDLINE 1946 to present. The specific terms used for the different search components were: (1) cerebral or brain or central nervous system (CNS), (2) CNS, (3) 1 OR 2, (4) pig or pigs or piglet or piglets or swine or swines or landrace or porcine or minipig or minipigs, (5) 3 and 4, (6) propofol or remifentanil or TIVA, (7) TIVA, (8) TIVA, (9) 6 or 7 or 8, (10) 5 and 9, (11) guinea or guineapig or guineapigs or guinea-pig or guinea-pigs, (12) 10 not 11 . The only filter applied was English, and the reference lists of relevant articles and recent reviews were hand-searched for additional studies. Three authors did the screening individually and any disagreement in selection were settled by mutual agreement.

Studies that evaluated CPO and used propofol or remifentanil for TIVA in healthy pigs of all ages and breeds were included in the systematic review. This also included studies that only indirectly assessed the effect of propofol or remifentanil on CPO. Studies where additional anaesthetic drugs were given for maintenance of anaesthesia were excluded. Eligible records (Fig. 1) were retrieved in full text and screened for relevant anaesthesia protocols and outcome data.

\section{Data extraction}

This systematic review is based on the principles recommended by the SYRCLE collaboration [62] and O'Connors and Sargeant [63]. Primary outcome data relevant to this systematic review were any CPO parameter. Secondary outcome data extracted were publication year, study type, number of animals, breed, bodyweight, age, gender, doses of preanaesthetic and other medications, doses of propofol and remifentanil, and MAP.
Synthesis of the CPO-data was made on the basis of means, standard deviations and $95 \%$ confidence intervals and is discussed with regard to secondary outcome data. Standard errors of means were transformed to standard deviations. If not reported, animal age was estimated based on weight [64-66].

\section{Review \\ Search results}

The electronic search identified 99 articles in english, of which 29 were eligible after title and abstract screening. Of these, 19 studies were excluded after full text examination (Fig. 1). Of the10 peer-reviewed articles included in this review, only three had propofol or remifentanil anaesthesia as the primary study objective, and only two investigated the effect of anaesthesia on CPO (Table 3). The studies were published between 2001 and 2014, and all but one, were non-survival studies. Post-intervention data from the survival study were not included in this review.

\section{Animals}

Data from a total of 133 animals are included in this review. All studies used farm pigs. Eight of the studies used animals with a bodyweight between 16 and $33 \mathrm{~kg}$, while one used animals between 7.5 and $14.5 \mathrm{~kg}$ and another between 21.5 and $92.8 \mathrm{~kg}$. Seven studies used female and three used male pigs: none of the studies used both (Table 4).

\section{Anaesthesia}

Three studies used a combination of propofol and remifentanil, and seven studies used propofol alone (Table 3). In all studies, anaesthesia was induced with propofol intravenously (iv) (1-4 mg/kg) and maintained with propofol $(3-15 \mathrm{mg} / \mathrm{kg} / \mathrm{h})$. In 3 studies remifentanil was given in a dose range of $0.2-0.35 \mu \mathrm{g} / \mathrm{kg} / \mathrm{min}$. In addition to propofol and remifentanil infusion, Silva et al. [67] investigated the effect of a single intravenous bolus of $5 \mu \mathrm{g} / \mathrm{kg}$ remifentanil. Intramuscularly (im) 

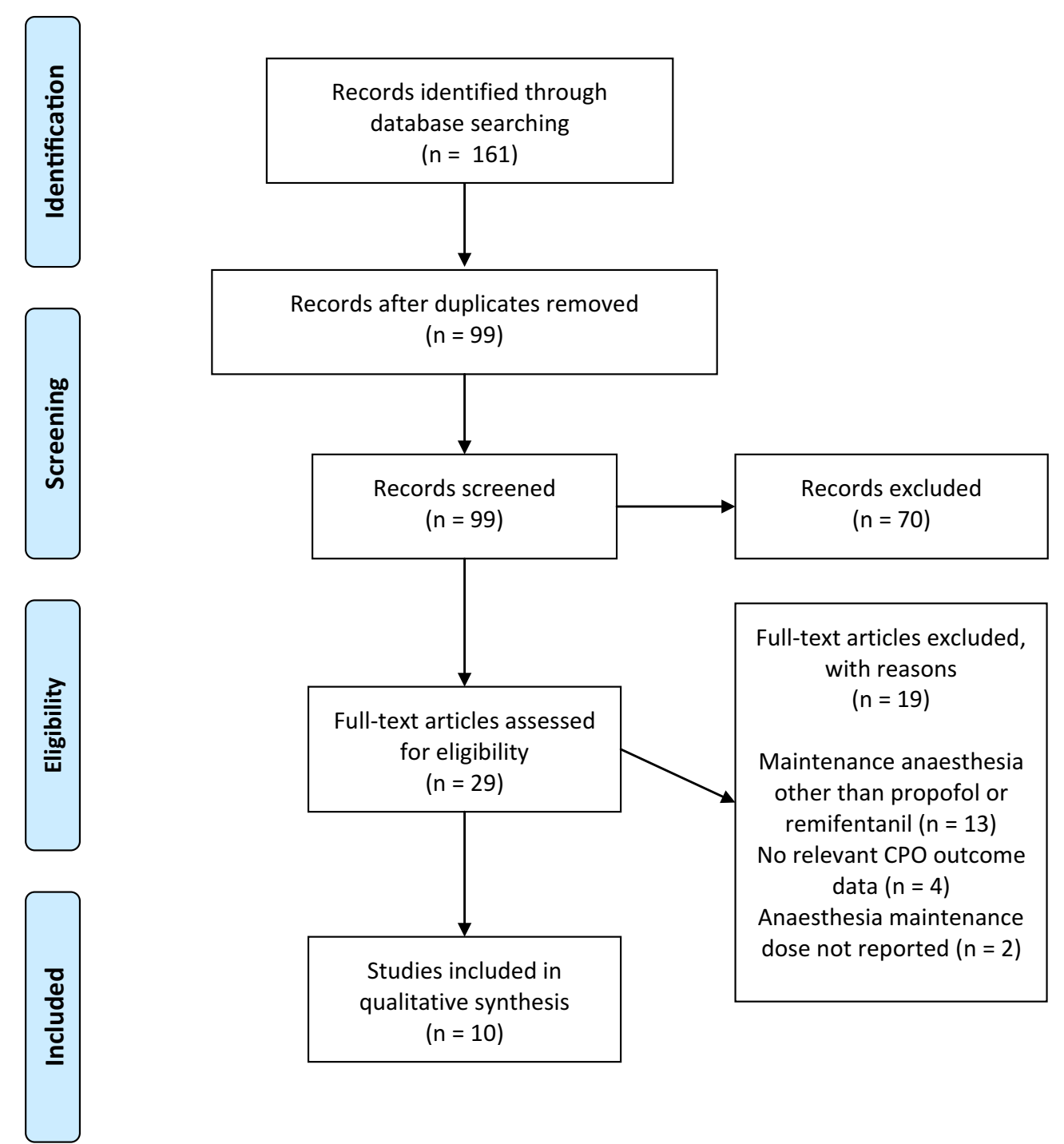

Fig. 1 PRISMA flow chart, Based on [102]

azaperone $4 \mathrm{mg} / \mathrm{kg}$ was used in two studies while ketamine, $10-33 \mathrm{mg} / \mathrm{kg} \mathrm{im}$, was used for premedication in eight of the studies. Six of these studies used ketamine alone, one added xylazine and one added xylazine, tiletamine and zolazepam. Single bolus pancuronium was used for muscle relaxation in one study [68], and flunixin, $2.2 \mathrm{mg} / \mathrm{kg}$ im was used pre-emptively for postoperative analgesia in one single survival study [69].

\section{Study design}

The included studies were animal intervention studies. Four studies used a 1-group design with pre-post-test assessment. Six 6 studies used a 2-group design of which 4 used random sequence allocation. Only Silva et al. [67] studied the effects of propofol-remifentanil anaesthesia on $\mathrm{CPO}$ as the primary objective. The remaining
9 studies did not have $\mathrm{CPO}$ in relation to anaesthesia as their primary objective. However, all were clear in their description of objectives and possible factors of influence are discussed below.

\section{Extracted data}

Predefined respiratory baseline limits were similar across studies, with target limits set at a respiratory rate of $10-14 / \mathrm{min}$, tidal volume of $10-20 \mathrm{ml} / \mathrm{kg}$, arterial $\mathrm{CO}_{2}\left(\mathrm{PaCO}_{2}\right)$ or end tidal $\mathrm{CO}_{2}\left(\mathrm{EtCO}_{2}\right)$ between 35 and $45 \mathrm{mmHg}$, arterial oxygen $\left(\mathrm{PaO}_{2}\right)>80 \mathrm{~mm} \mathrm{Hg}$ and oxygen saturation $\left(\mathrm{SpO}_{2}\right)>90 \%$. However, not all parameters were reported in all studies. Predefined haemodynamic baseline limits were not reported in detail in any of the studies, but Boezaart [68], Navarro et al. [70], Silva et al. [71] and Srinivasan et al. [72], reported that 
Tabel 3 Anaesthesia relevant data

\begin{tabular}{|c|c|c|c|}
\hline Study ID [reference] & Premedication. drug (dose ${ }^{a}$ ) & Propofol dose ${ }^{\mathbf{b}}$ (induction/maintenance) & Remifentanil dose \\
\hline Boezaart [68] & $\begin{array}{l}\text { Ketamine }(10 \mathrm{mg} / \mathrm{kg} \mathrm{im}) \\
\text { Pancuronium }(0.1 \mathrm{mg} / \mathrm{kg})\end{array}$ & $2.0 \mathrm{mg} / \mathrm{kg} / 3.0 \mathrm{mg} / \mathrm{kg} / \mathrm{h}$ & $0.35 \mathrm{mikrogram} / \mathrm{kg} / \mathrm{min}$ \\
\hline Kajimoto et al. [82] & $\begin{array}{l}\text { Ketamine }(33 \mathrm{mg} / \mathrm{kg} \mathrm{im}) \\
\text { xylazine }(2 \mathrm{mg} / \mathrm{kg} \mathrm{im})\end{array}$ & $\begin{array}{l}1.0-2.0 \mathrm{mg} / \mathrm{kg} / 15.0 \mathrm{mg} / \mathrm{kg} / \mathrm{h} \text { for } 15 \mathrm{~min} \text { then } \\
12.0 / \mathrm{mg} / \mathrm{h} \text { for } 45 \mathrm{~min} \text { then } 9.0 \mathrm{mg} / \mathrm{kg} / \mathrm{h} \text { for } \\
60 \mathrm{~min} \text { then } 7.5 \mathrm{mg} / \mathrm{kg} \text { for } 120 \mathrm{~min}\end{array}$ & Not used \\
\hline Lurie et al. [73] & Ketamine (21.9-25.0 mg/kg im) & $2.3 \mathrm{mg} / \mathrm{kg}+1.0 \mathrm{mg} / \mathrm{kg} / 9.6 \mathrm{mg} / \mathrm{kg} / \mathrm{h}$ & Not used \\
\hline Navarro et al. [70] & $\begin{array}{l}\text { Ketamine/Telazol/xylazine im (not } \\
\text { reported) }\end{array}$ & $1.5 \mathrm{mg} / \mathrm{kg} / 9.0 \mathrm{mg} / \mathrm{kg} / \mathrm{h}$ & Not used \\
\hline Silva et al. [71] & Azaperone (4 mg/kg im) & $4.0 \mathrm{mg} / \mathrm{kg} / 15.0 \mathrm{mg} / \mathrm{kg} / \mathrm{h}$ & $\begin{array}{l}0.3 \mathrm{mikrogram} / \mathrm{kg} / \mathrm{min} \text { followed } \\
\text { by } 0.2 \mathrm{mikrogram} / \mathrm{kg} / \mathrm{min}\end{array}$ \\
\hline Silva et al. [67] & Azaperone (4 mg/kg im) & $4.0 \mathrm{mg} / \mathrm{kg} / 15.0 \mathrm{mg} / \mathrm{kg} / \mathrm{h}$ & $\begin{array}{l}0.3 \mathrm{mikrogram} / \mathrm{kg} / \mathrm{min}+ \\
5 \mathrm{mikrogram} / \mathrm{kg} \text { bolus }\end{array}$ \\
\hline Srinivasan et al. [72] & Ketamine $(21.2-31.3 \mathrm{mg} / \mathrm{kg} \mathrm{im})^{\mathrm{c}}$ & $2.0-3.0 \mathrm{mg} / \mathrm{kg} / 9.6 \mathrm{mg} / \mathrm{kg}$ & Not used \\
\hline Yannopoulos et al. [100] & Ketamine (23.0-23.7 mg/kg im) & $1.0 \mathrm{mg} / \mathrm{kg} / 9.6 \mathrm{mg} / \mathrm{kg} / \mathrm{h}$ & Not used \\
\hline Yannopoulos et al. [101] & Ketamine (21.7-23.5 mg/kg im) & $2.0 \mathrm{mg} / \mathrm{kg} / 9.6 \mathrm{mg} / \mathrm{kg} / \mathrm{h}$ & Not used \\
\hline Yannopoulos et al. [69] & Ketamine (25.6-30.3 mg/kg im) & $2.3 \mathrm{mg} / \mathrm{kg} / 9.6 \mathrm{mg} / \mathrm{kg} / \mathrm{h}$ & Not used \\
\hline
\end{tabular}

a Doses are calculated based on animal weight

b Doses reported as mikrogram $/ \mathrm{kg} / \mathrm{min}$ are converted to $\mathrm{mg} / \mathrm{kg} / \mathrm{h}$ for easier comparison

c Calculated under the assumption that lowest dose was given to animals with lowest weight

Tabel 4 Animal and publication relevant data

\begin{tabular}{|c|c|c|c|c|c|c|}
\hline Study ID [reference] & $\begin{array}{l}\text { Animal } \\
\text { intervention study }\end{array}$ & $\begin{array}{l}\text { Random sequence } \\
\text { allocation }\end{array}$ & $\mathrm{n}$ & Gender/pig breed & $\begin{array}{l}\text { Weight } \\
(\mathbf{k g})^{\mathrm{a}}\end{array}$ & $\begin{array}{l}\text { Age in } \\
\text { weeks }\end{array}$ \\
\hline Boezaart [68] & 1 group & NA & 10 & Female/pigs & $22-28$ & $8-9^{b}$ \\
\hline Kajimoto et al. [82] & 2 groups & No & 14 & Male/yorkshire & $7.8-14.5$ & $4-6^{c}$ \\
\hline Lurie et al. [73] & 2 groups & Yes & 22 & Female/farm pigs & $30.4 \pm 1.3$ & $9-11^{b}$ \\
\hline Navarro et al. [70] & 1 group & NA & 6 & Female/swine & $21.5-92.8$ & $8-21^{b}$ \\
\hline Silva et al. [71] & 2 groups & Yes & 12 & Male/large white & $27.0 \pm 3.6$ & $12^{\mathrm{d}}$ \\
\hline Silva et al. [67] & 1 group & NA & 12 & Male/Large white & $26.2 \pm 3.6$ & $12^{d}$ \\
\hline Srinivasan et al. [72] & 1 group & NA & 13 & Female/domestic farm pigs & $16-33$ & $12-16$ \\
\hline Yannopoulos et al. [100] & 2 groups & Yes & 16 & Female/farm pigs & $30 \pm 0.5$ & $10-11^{b}$ \\
\hline Yannopoulos et al. [101] & 2 groups & No & 12 & Female/yorkshire-farm cross & $31 \pm 1.2$ & $10-11^{b}$ \\
\hline Yannopoulos et al. [69] & 2 groups & Yes & 16 & Female/farm pigs & $25.2 \pm 2.1$ & $8-9^{b}$ \\
\hline
\end{tabular}

$n$ : number of animals; NA: not applicable

a Mean \pm SD or upper and lower limits

b Age in weeks estimated from weight post hoc if not reported

c Reported as 27-41 days

d Reported as 3 months

haemodynamic baseline recordings had to be stable prior to intervention. MAP and the $95 \%$ confidence interval of all studies were within the limits of cerebral autoregulation (Table 5).

Cerebral blood flow was reported on the basis of directly measured transdural flow in tissue perfusion units, indirectly measured carotid artery blood flow in $\mathrm{ml} / \mathrm{min}$ or jugular venous oxygen saturation $\left(\mathrm{SvjO}_{2}\right)$ in \% or as cerebral perfusion pressure (CPP) in mm Hg. Mean
CPP was reported in four studies and ranged from 68 to $74.8 \mathrm{~mm} \mathrm{Hg}$ (Table 6).

Cerebral oxygenation was reported on the basis of direct measurement of brain tissue partial pressure of oxygen $\left(\mathrm{brPO}_{2}\right)$ in $\mathrm{mm} \mathrm{Hg}$ or indirect transcranial measurement of regional cerebral oxygen saturation $\left(\mathrm{rSO}_{2}\right)$ in $\%$. Data for brPO $\mathrm{O}_{2}$ from one study [73] was not reported in absolute values, but were extracted from a graph. Values for $\mathrm{rSO}_{2}$ between 51 and $65 \%$ were reported in three 
Table 5 Means and $95 \%$ confidence intervals of reported MAP

\begin{tabular}{lcllllc}
\hline Study ID [reference] & $\mathbf{n}$ & Outcome & Measure & Mean & Cl 95 \% (LL) & Cl 95 \% (UL) \\
\hline Boezaart [68] & 10 & MAP & $\mathrm{mm} \mathrm{Hg}$ & 89.0 & 82.6 & 95.4 \\
Kajimoto et al. [82] & 7 & MAP & $\mathrm{mm} \mathrm{Hg}$ & 69.0 & 63.1 & 74.9 \\
Lurie et al. [73] & 22 & MAP & $\mathrm{mm} \mathrm{Hg}$ & 91.8 & 85.3 & 70.0 \\
Navarro et al. [70] & 6 & MAP & $\mathrm{mm} \mathrm{Hg}$ & Range & 70.0 & 710.0 \\
Silva et al. [67] & 12 & MAP & $\mathrm{mm} \mathrm{Hg}$ & 72.7 & 67.4 & 78.0 \\
Silva et al. [71] & 12 & MAP & $\mathrm{mm} \mathrm{Hg}$ & 73.0 & 67.3 & 73.9 \\
Yannopoulos et al. [100] & 16 & MAP & $\mathrm{mm} \mathrm{Hg}$ & 81.0 & 73.9 & 88.1 \\
Yannopoulos et al. [101] & 12 & MAP & $\mathrm{mm} \mathrm{Hg}$ & 90.0 & 81.2 & 98.8 \\
Yannopoulos et al. [69] & 16 & MAPa & $\mathrm{mm} \mathrm{Hg}$ & 90.1 & 83.8 & 96.4 \\
\hline
\end{tabular}

$n$ : number of animals; MAP: mean arterial pressure; Cl: confidence interval; LL: lower limit; UL: upper limit

a Calculated from systolic and diastolic blood pressure

Table 6 Means and $95 \%$ confidence levels of reported cerebral perfusion measures

\begin{tabular}{|c|c|c|c|c|c|c|}
\hline Study ID [reference] & $\mathrm{n}$ & Outcome & Measure & Mean & $\mathrm{Cl} 95 \%$ (LL) & $\mathrm{Cl} 95 \%$ (UL) \\
\hline Boezaart [68] & 10 & CBF & TPU & 44.7 & 29.2 & 60.2 \\
\hline Lurie et al. [73] & 22 & CarotidBF & $\mathrm{ml} / \mathrm{min}$ & 119.4 & 101.8 & 136.9 \\
\hline Silva et al. [67] & 12 & SvjO2 & $\%$ & 82.7 & 77.0 & 88.3 \\
\hline Silva et al. [71] & 12 & $\mathrm{SvjO} 2$ & $\%$ & 79.0 & 73.9 & 84.1 \\
\hline Srinivasan et al. [72] & 13 & CPP & $\mathrm{mm} \mathrm{Hg}$ & 73.6 & 67.0 & 80.2 \\
\hline Yannopoulos et al. [69] & 16 & CarotidBF & $\mathrm{ml} / \mathrm{min}$ & 174.8 & 153.6 & 196.0 \\
\hline Yannopoulos et al. [100] & 16 & CPP & $\mathrm{mm} \mathrm{Hg}$ & 68.0 & 61.6 & 74.4 \\
\hline Yannopoulos et al. [101] & 12 & CPP & $\mathrm{mm} \mathrm{Hg}$ & 74.0 & 64.6 & 83.4 \\
\hline Yannopoulos et al. [69] & 16 & CPP & $\mathrm{mm} \mathrm{Hg}$ & 74.8 & 67.2 & 82.3 \\
\hline
\end{tabular}

n: number of animals; Cl: confidence interval; LL: lower limit; UL: upper limit; CBF: cerebral blood blow; CarotidBF: carotid blood flow; SvjO2: jugular venous haemoglobinoxygen saturation; CPP: cerebral perfusion pressure

studies while one study reported an $\mathrm{rSO}_{2}$ range from 65 to $80 \%$ (Table 7).

\section{Evaluation of the effects of propofol and remifentanil}

This systematic review was not able to identify studies with the primary objective to investigate the combined effects of propofol and remifentanil TIVA on cerebral perfusion and oxygenation in pigs. Thus, the question of how propofol and remifentanil affects CPO in healthy pigs remains uncertain. Silva et al. [67] investigated the effect of a single high dose remifentanil bolus $(5 \mu \mathrm{g} / \mathrm{kg}$ iv) on cerebral oxygenation during TIVA with propofol and remifentanil. They reported CPO outcome measures during propofol-remifentanil infusion (Tables 5, 6, 7), that were within the normal target limits, while a single bolus of remifentanil significantly lowered cerebral oxygenation, yet still within normal limits (Table 1). Silva et al. [67] suggest that this decrease may be associated with a decrease in cardiac output rather than altered cerebral metabolism. The primary aim of the remaining nine articles was not to

Table 7 Means and $95 \%$ confidence intervals of reported cerebral oxygenation measures

\begin{tabular}{|c|c|c|c|c|c|c|}
\hline Study ID [reference] & $\mathbf{n}$ & Outcome & Measure & Mean & Cl $95 \%$ (LL) & $\mathrm{Cl} 95 \%$ (UL) \\
\hline Kajimoto et al. [82] & 7 & rSO2 & $\%$ & 51.0 & 47.1 & 54.9 \\
\hline Lurie et al. [73] & 22 & $\mathrm{brPO}^{\mathrm{a}}$ & $\mathrm{mm} \mathrm{Hg}$ & 13.2 & 9.9 & 16.5 \\
\hline Navarro et al. [70] & 6 & rSO2 & $\%$ & Range & 65.0 & 80.0 \\
\hline Silva et al. [67] & 12 & $\mathrm{rSO} 2$ & $\%$ & 62.3 & 58.6 & 65.9 \\
\hline Silva et al. [71] & 12 & $\mathrm{rSO} 2$ & $\%$ & 65.0 & 61.6 & 68.4 \\
\hline
\end{tabular}

$n$ : number of animals; Cl: confidence interval; LL: lower limit; UL: upper limit; rSO2: regional cerebral oxygene saturation; brPO2: brain tissue partial pressure of oxygen

a Extrapolated from graph 
investigate the effects of propofol or propofol-remifentanil anaesthesia on CPO. Hence, data from these studies may have been influenced by factors other than anaesthesia with propofol or remifentanil. Beydon et al. [74] who studied bispectral index stability in response to haemodynamic instability, suggested that a propofol-remifentanil TIVA with a lower dose propofol $(8.4 \mathrm{mg} / \mathrm{kg} / \mathrm{h})$ and a higher dose of remifentanil $(0.54 \mu \mathrm{g} / \mathrm{kg} / \mathrm{min})$ provides a more stable anaesthetic depth compared to propofol-remifentanil TIVA with a higher dose of propofol $(26.7 \mathrm{mg} / \mathrm{kg} / \mathrm{h})$ and lower dose of remifentanil $(0.34 \mu \mathrm{g} /$ $\mathrm{kg} / \mathrm{min}$ ). Relative to the findings made by Beydon et al. [74], Boezaart et al. [68] used a very low dose of propofol for maintenance $(3 \mathrm{mg} / \mathrm{kg} / \mathrm{h})$ and a low dose of remifentanil, while the remainder of articles reviewed here, used a low-mid range propofol dose and a low remifentanil dose (Table 3). Silva et al. [71] defined a stable level of anaesthesia as total muscle relaxation, absence of palpebral reflex, and absence of hemodynamic response to interdigital space clamping. Srinivasan et al. [72] titrated anaesthesia on the basis of heart rate, blood pressure, tail and hoof response and spontaneous breathing. The depth of anaesthesia and consequently the stress response to surgical stimulation thus may differ between studies, which makes comparison difficult. None of the studies however, reported concerns about insufficient anaesthetic depth.

\section{Choice of model}

The studies included used farm pigs of different breeds that were only specified in 4 of the studies (Table 4). Farm pig breeding standards vary from country to country resulting in pig breeds of varying anatomy and physiology. When used in scientific studies thus, detailed consideration should be given to the choice of pig breed $[3,75]$. None of the studies reviewed here used mini or micro pig breeds but different farm pig breeds only, hence we find it acceptable to consider results as relatively comparable provided that age is taken into consideration. Based on the relationship between bodyweight and age, the animals included were approximately between 1 and 6 months old [64, 65]. For neurodevelopmental comparison to the human brain, it has been estimated that 1 week of life in the piglet approximates 1 month of life in humans [66]. Therefore, these animals could be considered equivalent to infants between 4 months and 2 years of age and may be the basis for a translational model of this paediatric subpopulation, while it seems less advisable to use this model in studies aiming at the human adult or geriatric subpopulation [76]. Cerebral autoregulation has been shown to be impaired more extensively in newborn than in juvenile pigs in response to traumatic brain injury [4], which indicates an age-dependent maturation of the cerebral autoregulatory response. Consequently, the youngest animals would be more sensitive to periods of hypotension (e.g. in response to anaesthetic induction) and potentially result in an over-interpretation of differing $\mathrm{CPO}$ responses between animals at both ends of the age span. This may explain the relatively broad range of $\mathrm{rSO}_{2}$ values in the study by Navarro et al. [70], since this study was conducted on few animals $(\mathrm{n}=6)$ with body weights ranging from 21.5 to $92.8 \mathrm{~kg}$ and estimated ages of approximately $8-21$ weeks. In parallel, the relatively wide range in MAP observed may also be a result of an uneven sensitivity to the propofol doses between animals with different age. As a result, an inter-animal comparison could be biased due to unequal physiological prerequisites, even if cerebral oxygenation was still within target limits for pigs.

Gender has been described as a factor influencing cerebral autoregulation in piglets $[77,78]$. None of the selected studies discussed the choice of animal gender.

\section{Anaesthesia and drug contamination}

Anaesthesia related discussion was brief and not given in all of the selected publications and main motivators for the choice of anaesthesia were animal welfare and analgesia while less attention was given to the potential influence of anaesthesia on their main outcome measures. Premedication was an integrated part of the anaesthetic protocol in all 10 studies and might influence outcome data, possibly in a dose dependent manner. Ketamine, which was used in eight out of the ten studies included in this review, is recommended for premedicationinduction and reduction of stress response in pigs [39]. Ketamine has also been reported to increase CBF, ICP, and cerebral metabolic rate at high doses in pigs [40, 45, 79-81]. None of the studies addressed the risk of drug contamination bias or length of washout periods, even though doses $\geq 30 \mathrm{mg} / \mathrm{kg}$ of ketamine were used for premedication in some of the studies [69, 72, 82]. However, from the trial descriptions we believe that the preparatory periods were long enough to reduce the risk of drug contamination bias in the assessed studies [83]. If this also is the case for the two studies [70,82] that combined ketamine premedication with either xylazine alone or ketamine with tiletamine, zolazepam and xylazine, is unclear. However another $\alpha_{2}$-agonist, medetomidine, has been reported to have a more prolonged effect on heart rate in minipigs [84] and xylazine has been reported to reduce local cerebral CBF in rats [85]. Azaperone, which was used for sedation in two studies (Table 3) has been reported to influence both cerebral and systemic haemodynamics, but is in general believed to have little influence on haemodynamics [86].

Boezaart [68] used pancuronium for muscle relaxation. High-dose pancuronium has been reported to widen the cerebral autoregulatory range in newborn piglets, but the 
single bolus of $0.1 \mathrm{mg} / \mathrm{kg}$, which was given at time of premedication is not expected to have influenced cerebral haemodynamics [87].

In one survival study [69] the nonsteroidal anti-inflammatory drug flunixin was given for post-operative analgesia intramuscularly, $1 \mathrm{~h}$ before surgical intervention. Flunixin has a relatively fast onset, and a long half-life of approximately $7 \mathrm{~h}$ in pigs [88]. The acute effect of flunixin on the haemodynamics of the normal pig brain has not been investigated, but other cyclooxygenase inhibitors have been reported to affect CBF when administered intravenously. Prostaglandin synthesis is cyclooxygenase dependent and plays a central role in maintaining CBF and cerebral autoregulation. It may be speculated that inhibition of prostaglandin synthesis by flunixin may influence CBF and consequently cerebral oxygenation [89]. The potential influence of flunixin on CPO assessment was not discussed by Yannopoulos et al. [69].

Premedication, in terms of dose, time from administration to the beginning of $\mathrm{CPO}$ measurement, and expected serum concentration of drugs and active metabolites is relevant to assessing the risk of drug related outcome contamination. Even though this is considered insignificant for primary outcome assessment, this was not addressed in any of the 10 articles reviewed.

\section{Methods of CPO measurements}

Monitoring CPO is a complex assessment of principally different variables such as systemic blood pressure, intra cranial pressure, tissue oxygen tension or haemoglobin saturation-all of which may be influenced by choice of monitoring technique $[1,20,31,90]$.

It is difficult to compare the cerebral perfusion measures reported in the selected articles. CBF was reported in 4 studies (Table 6). Lurie et al. [73] and Yannopoulos et al. [69] quantified a global measure of CBF by identical techniques of LDF over the exposed left common carotid artery. Lurie et al. [73] reported significantly lower values than Yannopoulos et al. [69] despite similar animal weight, gender and anaesthetic protocols. Yannopoulos et al. [69] additionally used $2.2 \mathrm{mg} / \mathrm{kg}$ flunixin im prior to surgery, which would be expected to reveal the opposite relationship, since flunixin in theory may have a CBF lowering effect. However, wide carotid blood flow limits have been reported earlier. Boezaart [68] also used LDF, but measured CBF locally through a drilled craniotomy, and reported it as relative tissue perfusion units, where the other studies reported it as absolute $\mathrm{ml} / \mathrm{min}$. Comparison of the CBF from the three studies is difficult because of the difference in measuring techniques, brain area of interest and wide normal flow limits [32, 91].

CPP was reported in four studies with a range between 68 and $74.8 \mathrm{mmHg}$, which is similar to previously reported CPP in healthy pigs anaesthetized with midazolam and fentanyl after ketamine and xylazine sedation [34]. More studies are required to verify this, and to determine a more exact range for CPP in pigs during different types of anaesthesia. Collectively however, none of the reported cerebral perfusion measures (Table 6) were outside the normal ranges for humans that are available in the literature (Table 1).

Cerebral oxygenation is a measure of oxygen available for consumption and energy metabolism in the brain. Lurie et al. [73] reported a mean $\mathrm{brPO}_{2}$ baseline value of $13.2 \mathrm{~mm} \mathrm{Hg}, 95 \% \mathrm{CI}$ [9.9-16.5 mm Hg]. This $\mathrm{brPO}_{2}$ is well outside the target ranges available in healthy swine of $25-30 \mathrm{~mm} \mathrm{Hg}$ [35] and further, is within the ischaemic range of $<15 \mathrm{~mm} \mathrm{Hg}$ in humans [1, 22, 92]. Lurie et al. [73] used the baseline as a relative comparison to post-interventional measures, however the relatively low $\mathrm{brPO}_{2}$ is not discussed in the article.

Non-invasive measurement of $\mathrm{rSO}_{2}$ with near infrared spectroscopy was performed in 4 studies and baseline values were reported for both propofol studies and for propofol and remifentanil studies (Table 7). Navarro et al. [70] reported an $\mathrm{rSO}_{2}$ range between 65 and $80 \%$ with the upper range slightly above the target range of 57-72 \% [36]. Kajimoto et al. [82] reported an $\mathrm{rSO}_{2}$ mean of $51 \%, 95 \%$ CI $(47.1 ; 54.9)$. This lower oxygenation measure could be related to the use of younger animals in this study and the high-dose ketamine and xylazine in the premedication used in this experiment. The earlier stage of neurodevelopment could render the animals more susceptible to sedative agents, which would lead to a more extensive metabolic cerebral depression and therefore lower oxygen demand.

\section{Conclusions}

Even though the very limited pool of evidence reviewed here, it suggests that propofol and remifentanil alone or in combination have limited effects on CPO in healthy pigs, confirmative evidence is lacking. In one study baseline $\mathrm{CPO}$ measures were within normal target ranges in healthy pigs during propofol-remifentanil TIVA. Addition of a single remifentanil dose significantly reduced $\mathrm{rSO}_{2}$ but not beyond normal target ranges.

There is a need for standardised porcine studies with the primary objective of studying the influence of anaesthetic drugs on $\mathrm{CPO}$ in non-diseased animals.

\footnotetext{
Abbreviations

$\mathrm{brPO}_{2}$ : brain tissue partial pressure of oxygen; CBF: cerebral blood flow; CPO: cerebral perfusion and oxygenation; CPP: cerebral perfusion pressure; LDF: laser Doppler flow; MAP: mean arterial pressure; $\mathrm{rSO}_{2}$ : regional cerebral oxygen saturation; $\mathrm{SvjO}_{2}$ : jugular venous oxygen saturation; TIVA: total intravenous anaesthesia.
} 


\section{Authors' contributions}

MLGM and TE conceived the overall objective, design and preliminary protocol for this systematic review. MLGM was responsible for building and conducting the primary literature search and drafting the manuscript. Record screening, secondary literature searches, extraction and interpretation of data were conducted in close collaboration with TE and RA. Data analysis and statistical revision was done in collaboration with JEM. FBM and HHP contributed with substantial intellectual guidance and interpretations of data, as well as critical revision of the manuscript in the topics of human and veterinary anaesthesia, respectively. All authors read and approved the final manuscript.

\section{Author details}

${ }^{1}$ Department of Veterinary Clinical and Animal Sciences, University of Copenhagen, 16 Dyrlægevej, 1870 Frederiksberg C, Denmark. ${ }^{2}$ Department of Surgical Gastroenterology C, Rigshospitalet, University of Copenhagen, 9 Blegdamsvej, 2100 Copenhagen $\varnothing$, Denmark. ${ }^{3}$ Department of Neuroanaesthesia, Rigshospitalet, University of Copenhagen, 9 Blegdamsvej, 2100 Copenhagen $\varnothing$, Denmark. ${ }^{4}$ Department of Anaesthesia, Sealand Hospital, University of Copenhagen, 1 Lykkebækvej, 4600 Køge, Denmark.

\section{Acknowledgements}

We would like to thank Rune Rasmussen for constructive discussion of the revised manuscript.

\section{Competing interests}

The authors declare that they have no competing interests.

Received: 10 March 2016 Accepted: 13 June 2016

Published online: 22 June 2016

\section{References}

1. Grocott HP, Davie S, Fedorow C. Monitoring of brain function in anesthesia and intensive care. Curr Opin Anesthesio. 2010;23:759-64.

2. Otto KA. Physiology, pathophysiology, and anesthetic management of patients with neurological disease. In: Grimm KA, Lamont LA, Tranquilli WJ, Greene SA, Robertson SA, editors. Veterinary Anesthesia and Analgesia - The fifth edition of Lumb and Jones. Ames lowa: Wiley; 2015. p. 559-83.

3. Lind NM, Moustgaard A, Jelsing J, Vajta G, Cumming P, Hansen AK. The use of pigs in neuroscience: modeling brain disorders. Neurosci Biobehav R. 2007;31:728-51.

4. Armstead WM. Age-dependent cerebral hemodynamic effects of traumatic brain injury in newborn and juvenile pigs. Microcirculation. 2000;7:225-35.

5. Swindle MM, Makin A, Herron AJ, Clubb FJ, Frazier KS. Swine as models in biomedical research and toxicology testing. Vet Pathol. 2012:49:344-56.

6. Malhotra AK, Schweitzer JB, Fox JL, Fabian TC, Proctor KG. Cerebral perfusion pressure directed therapy following traumatic brain injury and hypotension in swine. J Neurotraum. 2003;20:827-39.

7. Friess SH, Ralston J, Eucker SA, Helfaer MA, Smith C, Margulies SS. Neurocritical care monitoring correlates with neuropathology in a swine model of pediatric traumatic brain injury. Neurosurgery. 2011;69:1139-47.

8. Timaru-Kast R, Meissner A, Heimann A, Hoelper B, Kempski O, Alessandri B. Acute subdural hematoma in pigs: role of volume on multiparametric neuromonitoring and histology. J Neurotraum. 2008:25:1107-19.

9. Nilsson F, Akeson J, Messeter K, Ryding E, Rosen I, Nordstrom CH. A porcine model for evaluation of cerebral haemodynamics and metabolism during increased intracranial pressure. Acta Anaesth Scand. 1995:39:827-34

10. Andrade AF, Soares MS, Patriota GC, Belon AR, Paiva WS, Bor-SengShu E, et al. Experimental model of intracranial hypertension with continuous multiparametric monitoring in swine. Arq Neuro-Psiquiat. 2013;71:802-6.

11. Van Gompel JJ, Bower MR, Worrell GA, Stead M, Meier TR, Goerss SJ, et al. Swine model for translational research of invasive intracranial monitoring. Epilepsia. 2011:52:E49-53.
12. Kuluz JW, Prado R, He D, Zhao W, Dietrich WD, Watson B. New pediatric model of ischemic stroke in infant piglets by photothrombosis: acute changes in cerebral blood flow, microvasculature, and early histopathology. Stroke. 2007;38:1932-7.

13. Lucas SJ, Tzeng YC, Galvin SD, Thomas KN, Ogoh S, Ainslie PN. Influence of changes in blood pressure on cerebral perfusion and oxygenation. Hypertension. 2010;55:698-705.

14. Mishra LD. Cerebral blood flow and anaesthesia: a review. Indian J Anaesth. 2002;46:87-95.

15. Gupta AK, Azami J. Update of neuromonitoring. Curr Anaesth Crit Care. 2002;13:120-8.

16. Lassen NA. Cerebral blood flow and oxygen consumption in man Physiol Rev. 1959;39:183-238.

17. Prabhakar H, Sandhu K, Bhagat H, Durga P, Chawla R. Current concepts of optimal cerebral perfusion pressure in traumatic brain injury. J Anaesthesiol Clin Pharmacol. 2014:30:318-27.

18. Dagal A, Lam AM. Cerebral autoregulation and anesthesia. Curr Opin Anesthesio. 2009:22:547-52.

19. Smith AL, Neigh JL, Hoffman JC, Wollman H. Effects of general anesthesia on autoregulation of cerebral blood flow in man. J Appl Physio. 1970;29:665-9.

20. Smythe PR, Samra SK. Monitors of cerebral oxygenation. Anesthesiol Clin N A. 2002;20:293-313.

21. Moerman A, Hert S. Cerebral oximetry. The standard monitor of the future? Curr Opin Anesthesio. 2015;28:703-9.

22. Mahajan C, Rath GP, Bithal PK. Advances in neuro-monitoring. Anesth Essays Res. 2013;7:312-8.

23. Barone DG, Czosnyka M. Brain monitoring: do we need a hole? An update on invasive and noninvasive brain monitoring modalities. Sci World J. 2014. doi:10.1155/2014/795762 (eCollection 2014)

24. Le Roux P, Menon DK, Citerio G, Vespa P, Bader MK, Brophy GM, et al. Consensus summary statement of the International Multidisciplinary Consensus Conference on Multimodality Monitoring in Neurocritical Care: a statement for healthcare professionals from the Neurocritical Care Society and the European Society of Intensive Care Medicine. Neurocrit Care. 2014;21(Suppl 2):S1-26.

25. Benedik PS. Monitoring tissue blood flow and oxygenation: a brief review of emerging techniques. Crit Care Nurs Clin North Am. 2014;26:345-56

26. Kety SS, Schmidt CF. The nitrous oxide method for the quantitative determination of cerebral blood flow in man: theory, procedure and normal values. J Clin Invest. 1948:27:476-83.

27. Lassen NA, Munck O. The cerebral blood flow in man determined by the use of radioactive krypton. Acta Physiol Scand. 1955;33:30-49.

28. Ingvar DH, Cronqvist S, Ekberg R, Risberg J, Hoedt-Rasmussen K. Norma values of regional cerebral blood flow in man, including flow and weight estimates of gray and white matter. A preliminary summary. Acta Neurol Scand Suppl. 1965;14:72-8.

29. Ingvar DH, Lassen NA. Methods for cerebral bloodflow measurements in man. Br J Anaesth. 1965;37:216-24.

30. Parthasarathy AB, Weber EL, Richards LM, Fox DJ, Dunn AK. Laser speckle contrast imaging of cerebral blood flow in humans during neurosurgery. a pilot clinical study. J Biomed Opt. 2010;15:1-8.

31. Briers D, Duncan DD, Hirst E, Kirkpatrick SJ, Larsson M, Steenbergen W et al. Laser speckle contrast imaging: theoretical and practical limitations. J Biomed Opt. 2013. doi:10.1117/1.Jbo.18.6.066018.

32. Harada J, Takaku A, Endo S, Kuwayama N, Fukuda O. Differences in critical cerebral blood flow with age in swine. J Neurosurg. 1991;75:103-7.

33. Mutch WAC, Lefevre GR, Thiessen DB, Girling LG, Warrian RK. Computercontrolled cardiopulmonary bypass increases jugular venous oxygen saturation during rewarmin. Ann Thorac Surg. 1998;65:59-65.

34. Bruins B, Kilbaugh TJ, Margulies SS, Friess SH. The anesthetic effects on vasopressor modulation of cerebral blood flow in an immature swine model. Anesth Analg. 2013;116:838-44.

35. Maas Al, Fleckenstein W, de Jong DA, van Santbrink H. Monitoring cerebral oxygenation: experimental studies and preliminary clinical results of continuous monitoring of cerebrospinal fluid and brain tissue oxygen tension. Acta Neurochir Suppl (Wien). 1993:59:50-7.

36. Xanthos T, Bassiakou E, Koudouna E, Tsirikos-Karapanos N, Lelovas P, Papadimitriou D, et al. Baseline hemodynamics in anesthetized Landrace-Large White swine: reference values for research in cardiac 
arrest and cardiopulmonary resuscitation models. J Am Assoc Lab Anim Sci. 2007:46:21-5.

37. Kurth CD, Levy WJ, McCann J. Near-infrared spectroscopy cerebral oxygen saturation thresholds for hypoxia-ischemia in piglets. J Cereb Blood Flow Metab. 2002;22:335-41.

38. Wenzel V, Padosch SA, Voelckel WG, Idris AH, Krismer AC, BettschartWolfensberger R, Lindner KH. Survey of effects of anesthesia protocols on hemodynamic variables in porcine cardiopulmonary resuscitation laboratory models before induction of cardiac arrest. Comp Med. 2000;50:644-8.

39. Alstrup AKO, Smith DF. Anaesthesia for positron emission tomography scanning of animal brains. Lab Anim. 2013;47:12-8.

40. Cole CD, Gottfried ON, Gupta DK, Couldwell WT. Total intravenous anesthesia: advantages for intracranial surgery. Neurosurgery. 2007;59(Suppl 2):369-77.

41. Lagerkranser M, Stange K, Sollevi A. Effects of propofol on cerebral blood flow, metabolism, and cerebral autoregulation in the anesthetized pig. J Neurosurg Anesth. 1997:9:188-93.

42. Veselis RA, Reinsel RA, Beattie BJ, Mawlawi OR, Feshchenko VA, DiResta GR, et al. Midazolam changes cerebral blood flow in discrete brain regions: an $\mathrm{H} 2(15) \mathrm{O}$ positron emission tomography study. Anesthesiology. 1997;87:1106-17.

43. Kaisti KK, Langsjo JW, Aalto S, Oikonen V, Sipila H, Teras M, et al. Effects of sevoflurane, propofol, and adjunct nitrous oxide on regional cerebral blood flow, oxygen consumption, and blood volume in humans. Anesthesiology. 2003;99:603-13.

44. Bonhomme V, Boveroux P, Hans P, Brichant JF, Vanhaudenhuyse A, Boly $M$, et al. Influence of anesthesia on cerebral blood flow, cerebral metabolic rate, and brain functional connectivity. Curr Opin Anaesthesio. 2011;24:474-9.

45. Langsjo JW, Maksimow A, Salmi E, Kaisti K, Aalto S, Oikonen V, et al. S-ketamine anesthesia increases cerebral blood flow in excess of the metabolic needs in humans. Anesthesiology. 2005;103:258-68.

46. Hans P, Bonhomme V. Why we still use intravenous drugs as the basic regimen for neurosurgical anaesthesia. Curr Opin Anaesthesio. 2006;19:498-503.

47. Schifilliti D, Grasso G, Conti A, Fodale V. Anaesthetic-related neuroprotection. intravenous or inhalational agents? CNS Drugs. 2010;24:893-907.

48. Chui J, Mariappan R, Mehta J, Manninen P, Venkatraghavan L. Comparison of propofol and volatile agents for maintenance of anesthesia during elective craniotomy procedures: systematic review and metaanalysis. Can J Anaesth. 2014;61:347-56.

49. Lauder GR. Total intravenous anesthesia will supercede inhalational anesthesia in pediatric anesthetic practice. Paediatr Anaesth. 2015;25:52-64.

50. Engelhard K, Werner C, Mollenberg O, Kochs E. Effects of remifentanil/ propofol in comparison with isoflurane on dynamic cerebrovascular autoregulation in humans. Acta Anaesth Scand. 2001;45:971-6.

51. Conti A, lacopino DG, Fodale V, Micalizzi S, Penna O, Santamaria LB. Cerebral haemodynamic changes during propofol-remifentanil or sevoflurane anaesthesia: transcranial Doppler study under bispectral index monitoring. Br J Anaesth. 2006;97:333-9.

52. Kay B, Rolly G. I.C.I. 35868, a new intravenous induction agent. Acta Anaesthesiol Belgica. 1977;28:303-16.

53. Berry SH. Injectable anesthetics. In: Grimm KA, Lamont LA, Tranquilli WJ, Greene SA, Robertson SA, editors. Veterinary anesthesia and analgesia - the fifth edition of Lumb and Jones. Ames lowa: Wiley; 2015. p. 559-83.

54. Eikaas $\mathrm{H}$, Raeder J. Total intravenous anaesthesia techniques for ambulatory surgery. Curr Opin Anaesthesio. 2009;22:725-9.

55. Marik PE. Propofol: therapeutic indications and side-effects. Curr Pharm Des. 2004;10:3639-49.

56. Adembri C, Venturi L, Pellegrini-Giampietro DE. Neuroprotective effects of propofol in acute cerebral injury. CNS Drug Rev. 2007;13:333-51.

57. Kotani Y, Shimazawa M, Yoshimura S, I wama T, Hara H. The experimental and clinical pharmacology of propofol, an anesthetic agent with neuroprotective properties. CNS Neurosci Ther. 2008;14:95-106.

58. Servin FS, Billard V. Remifentanil and other opioids. Hand Exp Pharmacol. 2008;182:283-311.
59. Fodale V, Schifilliti D, Praticò C, Santamaria LB. Remifentanil and the brain. Acta Anaesth Scand. 2008;52:319-26.

60. Klimscha W, Ullrich R, Nasel C, Dietrich W, Illievich UM, Wildling E, et al. High-dose remifentanil does not impair cerebrovascular carbon dioxide reactivity in healthy male volunteers. Anesthesiology. 2003;99:834-40.

61. Baker KZ, Ostapkovich N, Sisti MB, Warner DS, Young WL. Intact cerebral blood flow reactivity during remifentanil/nitrous oxide anesthesia. J Neurosurg Anesth. 1997;9:134-40.

62. Hooijmans CR, Rovers MM, de Vries RB, Leenaars M, Ritskes-Hoitinga M, Langendam MW. SYRCLE's risk of bias tool for animal studies. BMC Med Res Methodol. 2014:14:43. doi:10.1186/1471-2288-14-43.

63. O'Connor AM, Sargeant JM. Critical appraisal of studies using laboratory animal models. ILAR J. 2014;55:405-17.

64. Pond WG. Biology of the domestic pig. Ithaca: Comstock Publishing Associates; 2001.

65. Swindle MM. Swine in the laboratory: surgery, anesthesia, imaging, and experimental techniques. 2nd ed. Boca Raton: CRC Press; 2007.

66. Conrad MS, Johnson RW. The domestic piglet: an important model for investigating the neurodevelopmental consequences of early life insults. Annu Rev Anim Biosci. 2015;3:245-64.

67. Silva A, Venancio C, Ortiz AL, Souza AP, Amorim P, Ferreira DA. The effect of high doses of remifentanil in brain near-infrared spectroscopy and in electroencephalographic parameters in pigs. Vet Anaesth Analg. 2014;41:153-62.

68. Boezaart AP. Effects of cerebrospinal fluid loss and epidural blood patch on cerebral blood flow in swine. Region Anesth Pain M. 2001;26:401-6.

69. Yannopoulos D, Matsuura T, McKnite S, Goodman N, Idris A, Tang WC, et al. No assisted ventilation cardiopulmonary resuscitation and 24-hour neurological outcomes in a porcine model of cardiac arrest. Crit Care Med. 2010;38:254-60.

70. Navarro LH, Lima RM, Khan M, Dominguez WG, Voigt RB. Kinsky MP et cardiovascular status during hemorrhagic shock in a swine model. J Trauma Acute Care Surg. 2012:73(Suppl 1):S140-6.

71. Silva A, Ortiz AL, Venancio C, Souza AP, Ferreira LM, Branco PS, et al. Effects of acute bleeding followed by hydroxyethyl starch 130/0.4 or a crystalloid on propofol concentrations, cerebral oxygenation, and electroencephalographic and haemodynamic variables in pigs. Vet. Med Int. 2014. doi:10.1155/2014/710394.

72. Srinivasan V, Nadkarni VM, Yannopoulos D, Marino BS, Sigurdsson G, McKnite $\mathrm{SH}$, et al. Spontaneous gasping decreases intracranial pressure and improves cerebral perfusion in a pig model of ventricular fibrillation. Resuscitation. 2006;69:329-34.

73. Lurie KG, Yannopoulos D, McKnite SH, Herman ML, Dris AH, Nadkarni VM, et al. Comparison of a 10-breaths-per-minute versus a 2-breathsper-minute strategy during cardiopulmonary resuscitation in a porcine model of cardiac arrest. Resp Care. 2008:53:862-70.

74. Beydon L, Desfontis JC, Ganster F, Petres J, Gautier F, Ferec S, et al. BIS response to tamponade and dobutamine in swine varies with hypnotic/opiate ratio. Ann Fr Anesth. 2009;28:650-7.

75. Bollen PJA, Hansen AK, Alstrup AKO. The Laboratory Swine. 2nd ed. Boca Raton: CRC Press; 2010.

76. Zisowsky J, Krause A, Dingemanse J. drug development for pediatric populations: regulatory aspects. Pharmaceutics. 2010;2:364-88.

77. Armstead WM, Kiessling JW, Kofke WA, Vavilala MS. Impaired cerebral blood flow autoregulation during posttraumatic arterial hypotension after fluid percussion brain injury is prevented by phenylephrine in female but exacerbated in male piglets by extracellular signal-related kinase mitogen-activated protein kinase upregulation. Crit Care Med. 2010;38:1868-74

78. Armstead WM, Kiessling JW, Riley J, Kofke WA, Vavilala MS. Phenylephrine infusion prevents impairment of ATP- and calcium-sensitive potassium channel-mediated cerebrovasodilation after brain injury in female, but aggravates impairment in male, piglets through modulation of ERK MAPK upregulation. J Neurotraum. 2011;28:105-11.

79. Akeson J, Bjorkman S, Messeter K, Rosen I, Helfer M. Cerebral pharmacodynamics of anaesthetic and subanaesthetic doses of ketamine in the normoventilated pig. Acta Anaesth Scand. 1993;37:211-8.

80. Schmidt A, Ryding E, Akeson J. Racemic ketamine does not abolish cerebrovascular autoregulation in the pig. Acta Anaesth Scand. 2003:47:569-75. 
81. Schmidt A, Oye I, Akeson J. Cerebral physiological responses to bolus injection of racemic, S(+)- or R(-)-ketamine in the pig. Acta Anaesth Scand. 2005;49:1436-42.

82. Kajimoto M, Atkinson DB, Ledee DR, Kayser EB, Morgan PG, Sedensky $M M$, et al. Propofol compared with isoflurane inhibits mitochondrial metabolism in immature swine cerebral cortex. J Cereb Blood Flow Met. 2014;34:514-21.

83. Bjorkman S, Akeson J, Nilsson F, Messeter K, Roth B. Ketamine and midazolam decrease cerebral blood flow and consequently their own rate of transport to the brain: an application of mass balance pharmacokinetics with a changing regional blood flow. J Pharmacokinet Biop. 1992;20:637-52

84. Authier S, Gervais J, Fournier S, Gauvin D, Maghezzi S, Troncy E. Cardiovascular and respiratory safety pharmacology in Göttingen minipigs. Pharmacological characterization. J Pharmacol Toxicol. 2011:64:53-9.

85. Lei H, Grinberg O, Nwaigwe Cl, Hou HG, Williams H, Swartz HM, et al. The effects of ketamine-xylazine anesthesia on cerebral blood flow and oxygenation observed using nuclear magnetic resonance perfusion imaging and electron paramagnetic resonance oximetry. Brain Res. 2001;913:174-9.

86. van Woerkens $L J$, Duncker DJ, Huigen RJ, van der Giessen WJ, Verdouw PD. Redistribution of cardiac output caused by opening of arteriovenous anastomoses by a combination of azaperone and metomidate. Br J Anaesth. 1990;65:393-9.

87. Chemtob S, Barna T, Beharry K, Aranda JV. Enhanced cerebral blood flow autoregulation in the newborn piglet by $d$-tubocurarine and pancuronium but not by vecuronium. Anesthesiology. 1992;76:236-44.

88. Pairis-Garcia MD, Karriker LA, Johnson AK, Kukanich B, Wulf L, Sander $S$, et al. Pharmacokinetics of flunixin meglumine in mature swine after intravenous, intramuscular and oral administration. BMC Vet Res. 2013. doi:10.1186/1746-6148-9-165.

89. Schiefecker AJ, Pfausler B, Beer R, Sohm F, Sabo J, Knauseder V, et al. Parenteral diclofenac infusion significantly decreases brain-tissue oxygen tension in patients with poor-grade aneurysmal subarachnoid hemorrhage. Crit Care. 2013. doi:10.1186/cc12714.

90. Nathanson M, Moppett IK, Wiles M. Neuroanaesthesia. Oxford: Oxford University Press; 2011

91. Udassi JP, Udassi S, Shih A, Lamb MA, Porvasnik SL, Zaritsky AL, et al. Novel adhesive glove device (AGD) for active compression-decompression (ACD) CPR results in improved carotid blood flow and coronary perfusion pressure in piglet model of cardiac arrest. Resuscitation. 2012;83:750-4.
92. Brain Trauma Foundation. Guidelines for the management of severe traumatic brain injury. J Neurotraum. 2007;24(Suppl 1):S3-6.

93. El Beheiry H. Protecting the brain during neurosurgical procedures: strategies that can work. Curr Opin Anaesthesio. 2012;25:548-55.

94. Veenith T, Menon DK. The cerebral circulation. In: Matta BF, Menon DK, Smith $\mathrm{M}$, editors. Core topics in neuroanaesthesia and neurointensive care. Cambridge: Cambridge University Press; 2011. p. 17-21.

95. Ford MD, Alperin N, Lee SH, Holdsworth DW, Steinman DA. Characterization of volumetric flow rate waveforms in the normal internal carotid and vertebral arteries. Physiol Meas. 2005;26:477-88.

96. Artru AA, Shapira Y, Bowdle TA. Electroencephalogram, cerebral metabolic, and vascular responses to propofol anesthesia in dogs. J Neurosurg. Anesth. 1992;4:99-109.

97. Hoffman WE, Cunningham F, James MK, Baughman VL, Albrecht RF. Effects of remifentanil, a new short-acting opiod, on cerebral blood flow, brain electric activity, and intracranial pressure in dogs anesthetized with isoflurane and nitrous oxide. Anesthesiology. 1993;79:107-13.

98. Ramani R, Todd MM, Warner DS. A dose response study of the influence of propofol on cerebral blood flow, metabolism and the electroencephalogram in the rabbit. J Neurosurg Anesth. 1992:4:110-9.

99. Werner C, Hoffman WE, Kochs E. Schulte am Esch J, Albrecht RF. The effects of propofol on cerebral spinal cord blood flow in rats. Anesth Analg. 1993;76:971-5

100. Yannopoulos D, Aufderheide TP, McKnite S, Kotsifas K, Charris R, Nadkarni $V$, et al. Hemodynamic and respiratory effects of negative tracheal pressure during CPR in pigs. Resuscitation. 2006;69:487-94.

101. Yannopoulos D, Metzger A, McKnite S, Nadkarni V, Aufderheide TP, Idris $A$, et al. Intrathoracic pressure regulation improves vital organ perfusion pressures in normovolemic and hypovolemic pigs. Resuscitation. 2006;70:445-53.

102. Moher D, Liberati A, Tetzlaff J, Altman DG. The PRISMA Group. Preferred Reporting Items for Systematic Reviews and Meta-Analyses: the PRISMA Statement. PLoS Med. 2009. doi:10.1371/journal.pmed1000097.

\section{Submit your next manuscript to BioMed Central and we will help you at every step:}

- We accept pre-submission inquiries

- Our selector tool helps you to find the most relevant journal

- We provide round the clock customer support

- Convenient online submission

- Thorough peer review

- Inclusion in PubMed and all major indexing services

- Maximum visibility for your research

Submit your manuscript at www.biomedcentral.com/submit
BioMed Central 